\title{
PHASES IN THE S-GENE EXPRESSION, AND S-ALLELE INTERACTION IN THE CONTROL OF INTERSPECIFIC INCOMPATIBILITY
}

\author{
KAMLA KANT PANDEY \\ Genetics Unit, Grosslands Division, D.S.I.R., Polmerston North, \\ New Zealand
}

Received 1.i.73

\section{SumMaRY}

Plants of 19 progeny families, grown from seeds obtained from crosses between five different $S$ genotypes of Nicotiana bonariensis, were studied for their interspecific incompatibility behaviour as female parents with pollen of certain S.I. and S.C. species.

The relationship between $S$ genotypic constitution and interspecific incompatibility behaviour, first shown by the plants of the parental families studied earlier, was confirmed without exception in all the progenies. All plants of the same $S$ genotypic constitution always behaved alike. No dissociation of specific intra- and interspecific incompatibility reactions has been found in a total of 1200 plants so far tested in $\mathcal{N}$. alata and $\mathcal{N}$. bonariensis.

Study of the 10 genotypes possible from four different $S$ alleles, six heterozygous and four homozygous, taken in conjunction with the earlier studies in this species, showed that interspecific incompatibility, including unilateral incompatibility, was the function of $S$ alleles. Each $S$ allele had its own specific property of accepting or rejecting a class of pollen.

There is a truly sporophytic determination of interspecific incompatibility in the style. In styles heterozygous for $S$ alleles there was either independent action, or allelic interaction between the accepting and the rejecting allele showing dominance of one or the other.

The allelic interactions in the style are specific for pollen of particular species, and have no relationship with allelic behaviour in connection with pollen of other species.

Generally, all pollen of a species behaved alike, polymorphism occurring only in the style behaviour. The tester S.I. plant GM8 of otherwise S.C. species $\mathcal{N}$. glauca is an exception. The pollen of this plant differed in interspecific incompatibility behaviour from a number of other S.I. plants of this species tested, which were, as expected, all alike in this respect.

The S.I. plant GM8 is $S$ heterozygous with two distinct forms of $S$ alleles, a usual self-incompatibility allele $S_{I}$, and a self-compatibility allele $S_{C}$ which when present alone in the pollen causes that pollen to be rejected by a S.I. style. The unusual behaviour of the plant GM8 $\left(S_{I} S_{C}\right)$ is due to $S$ allele interaction in the pollen. All other S.I. plants, with usual behaviour of their pollen, are $S$ homozygous with two different $S$ alleles of the same $S_{I}$ form. GM8.

The results suggest a sporophytic action of the $S_{C}$ gene in the pollen of

There are two phases in the physiology of the $S$-gene action: (i) a primary $S$-gene action phase which occurs independently in the pollen and style and (ii) a secondary, incompatibility reaction phase which occurs after the pollen and style have come in contact with each other. Allelic interaction may occur in one or both phases.

There are stepwise differences in the extent of rejection of the pollen of S.C. plants having different forms of $S$ alleles, starting at the one end with full acceptance of the comparatively young self-compatible " $S_{0}$ " class of pollen by S.I. styles to the other end with complete rejection of the comparatively ancient self-compatible " $S_{C_{n}}$ " class of pollen $\left(S_{C_{1}}, S_{C_{2}}, \ldots\right.$, etc.) by S.I. styles.

It is suggested that the $S_{0}$ class of self-compatible pollen, along with the 
usual $S_{I}$ class of pollen, has a gametophytic action of the $S$ gene whereas the $S_{f}, S_{C}$ and $S_{C n}$ classes of pollen containing a relatively " eroded "form of the $S$ gene have a sporophytic or partially sporophytic action.

\section{Introduction}

SUPERGENES, closely linked physiologically integrated clusters of loci acting as one gene, are often associated with polymorphism. They have been found in primroses, snails, slugs, Lepidoptera, grouse locusts, Drosophila, grasshoppers and man, and, no doubt, occur widely in plants and animals alike (Darlington and Mather, 1949; Sheppard, 1953; Darlington, 1958, 1971 ; Ford, 1964). The supergene $S$ as a gene complex governing morphological and physiological polymorphisms involved in the control of intraspecific incompatibility in heteromorphic and homomorphic flowering plants is well known (East and Mangelsdorf, 1925; Mather and de Winton, 1941 ; Lewis, 1949, 1954; Mather, 1955). The realisation that the $S$ complex may also be involved in the control of interspecific incompatibility, however, is recent (Lewis, 1954a; Lewis and Crowe, 1958; Pandey, 1961, 1962a, 1964), although certain evidence in this direction was available as early as 1931 .

Anderson and de Winton (1931) in Nicotiana and Mather (1943) in Petunia demonstrated that certain self-incompatibility alleles, when present in the style, had the property of rejecting not only pollen containing the same allele but also pollen of certain related self-compatible species. Recently this finding was confirmed with the rediscovery of such alleles, now called $S_{F I}$, in Nicotiana alata (Pandey, 1964, 1967). These alleles, of which only two forms, $S_{\mathrm{F} 10}$ and $S_{\mathrm{F} 11}$, have been found so far in nature, when present in the style, cause that style to reject pollen of the related self-compatible species Nicotiana langsdorffi, whereas the presence of the more numerous $S_{I}$ alleles allows the style to accept that pollen. The study of the $F_{1}, F_{2}$, budselfed and backcrossed progeny all suggested that (l) the interspecific incompatibility between $\mathcal{N}$. alata and $\mathcal{N}$. langsdorffi was the function of the $S_{F I}$ alleles alone and did not involve any other major factor; and (2) the two specificities controlling intra- and interspecific incompatibility were closely linked so that no dissociation between these two characteristics occurred in the several hundred plants studied.

In a recent study of $S$-gene polymorphism in the self-incompatible species $\mathcal{N}$. bonariensis, a large number of plants comprising four families, 8746, 9503, 9584a and 9584b, grown from seeds obtained from different sources, were tested as females for their cross-compatibility behaviour with two testers, self-compatible species $\mathcal{N}$. langsdorffi (N.I.) and a self-incompatible strain (GM8) of an otherwise self-compatible species $\mathcal{N}$. glauca (Pandey, 1969a). All four possible kinds of cross-compatibility relationships were observed, thus dividing the plants into four groups, henceforth called "polymorphic classes " $(-=$ Incompatible; $+=$ Compatible $)$ :

$\begin{array}{ccc}\text { Polymorphic class } & \text { N.1. } & \text { GM8 } \\ \text { A } & - & + \\ \text { B } & + & - \\ \text { C } & + & + \\ \text { D } & - & -\end{array}$


There was a strict relationship between the different polymorphic classes and the $S$ genotypic constitutions; all plants of the same $S$ constitution were identical in their cross-compatibility behaviour and therefore belonged to the same polymorphic class. However, more than one $S$ genotype could belong to the same polymorphic class. Of the six available genotypes (I-VI) two, I and III, were identical with the polymorphic classes A and $\mathrm{G}$ respectively; of the remaining four genotypes two, II and VI, fell into the same polymorphic class $B$ and two, IV and V, into class $D$. These results strongly suggested the involvement of $S$ alleles in the control of interspecific incompatibility.

In order to test the above hypothesis further, progeny of a number of crosses, involving five of the six $S$ genotypes, were studied for their $S$ genotypes and cross-compatibility relationships with the two testers. Also, a comparative study was made of the heterozygous and the $S$-allele homozygous genotypes, obtained through bud-self-pollination, in relation to these two and other testers. The results confirm the major role of the $S$ alleles in the control of interspecific incompatibility, and throw significant light on the nature of interspecific incompatibility and S-allele polymorphism.

Earlier work on the $S$-allele interactions in the diploid pollen of autotetraploids (Lewis, 1947; Pandey, 1956a, 1962c) suggested that there are two components of the $S$-gene expression in the control of incompatibility: (1) one which is expressed in the pollen and style independently, before they come in contact with each other, and (2) another which is expressed, as an incompatibility or compatibility reaction, when the two come in contact with each other after pollination. The present study provides a much clearer picture of the two phases in the $S$-gene physiology controlling the incompatibility reaction.

\section{Materials and methods}

A description of the sources of seed of Nicotiana bonariensis, the two regular pollen testers, self-compatible (S.C.) $\mathcal{N}$. langsdorffi and a self-incompatible (S.I.) strain GM8 of otherwise S.C. $\mathcal{N}$. glauca, and three other testers, $\mathcal{N}$. alata, $\mathcal{N}$. forgetiana and $\mathcal{N}$. noctiflora, has been given in earlier papers (Pandey, 1964, 1967, 1968, 1969a). Seed of the sixth tester, $\mathcal{N}$. longiflora, varieties grandiflora and breviflora, was obtained from U.S.D.A., Beltsville, Maryland, U.S.A.

In $\mathcal{N}$. glauca, a predominantly self-compatible species, until recently only one S.I. plant, GM8, was available for use in these experiments. A family of bud-selfed progeny of this plant contained three S.I. and two S.C. plants. Tests on these plants showed that plant GM8 was heterozygous, $S_{I} S_{C}$. Fresh seed of this species was obtained from Argentina through the courtesy of the Director, Botany Division, D.S.I.R., Christchurch. All but two of the 30 plants grown from this seed were S.I. (The results of a detailed study of $S$-allele polymorphism in $\mathcal{N}$. glauca are to be published later.) In the present study four of the S.I. and the two S.C. plants, arising from the later stock, were included as testers.

The cytological technique involved in the study of pollen-tube growth, the technique of producing selfed-seed in S.I. plants through bud-selfpollination, and the growing conditions of the plants have all been described previously (Pandey, 1962b, 1963, 1964). 
Two or more crosses were made in each combination studied. All crosses that failed to produce seed were examined for pollen-tube growth in the style.

\section{RESUlTS AND INTERPRETATIONS}

\section{(i) Crosses between apparently normal parents}

The parental plants for these crosses were drawn from two families, 8746 and 9503 , which between them contained five $S$ genotypes and all four polymorphic classes: I (A), II (B), III (C), IV and V (D). In all, 19 progeny families were studied. All progenies were selfed, and crossed as females with two interspecific testers, N.l. and GM8, and the six intraspecific testers, the $S$ genotypes. After the $S$ genotypes in each family were identified the existence of the intra-incompatible inter-compatible groups was confirmed by intercrossing eight plants comprising a few plants from each group. The identities of $S$ genotypes were rechecked by crossing between genotypic groups obtained from different families.

The results of test crosses are given in table 1. The same six genotypes found among the original plants were again found in the progeny. No new genotypes were recovered. The $S$ genotypes found in each family generally agreed with the expectation based on the 1-locus gametophytic system of incompatibility, and, with a few exceptions, expected genotypes according to the given genotypic constitution of the parents were usually recovered in the progenies. The exceptions included the family 9610 , which was expected to yield two genotypes, but in which all 16 plants belonged to one genotype. Similarly, in the family 9577 where four genotypes were expected, only two genotypes were recovered among the 13 plants studied. The lack of certain genotypes in some of the families, where the total number of plants studied was probably high enough to have yielded all the expected genotypes, may be due to $S$-genotype linked zygotic lethality and inviability of seed, and is perhaps associated with the inbreeding depression. The earlier detailed work on this species (Pandey, 1969a) had suggested that although seed material was obtained from four different sources they probably had a common origin from a set of two plants differing in both alleles. Same $S$ genotypes, totalling six, were recovered from different materials. The conclusion that the main cause of the abnormality lies in linkage and inbreeding depression, and not in any other genetic phenomenon, is supported by the facts (1) that a number of compatible crosses in these experiments yielded poor seed set and gave very poor germination; and (2) that in some families where all expected genotypes were recovered the number of plants in certain genotypes was extremely low-e.g. in families 9611 (17 and 2), 9589 (8 and 1), 9591 (19 and 2) and 9573 (11 and 1)--indicating that in slightly different circumstances these latter genotypes might not have been recovered at all.

The results of crosses of progenies with species testers, N.1. and GM8, were invariably in conformity with that expected on the basis of their $S$ genotypes. No exceptional plants dissociating the interspecific and intraspecific specificities were discovered. Where the two parents belonged to the same polymorphic class (D), as in the family $9605(\mathrm{~V} \times \mathrm{IV})$, the progeny, as expected, comprised two polymorphic classes (B and D). 


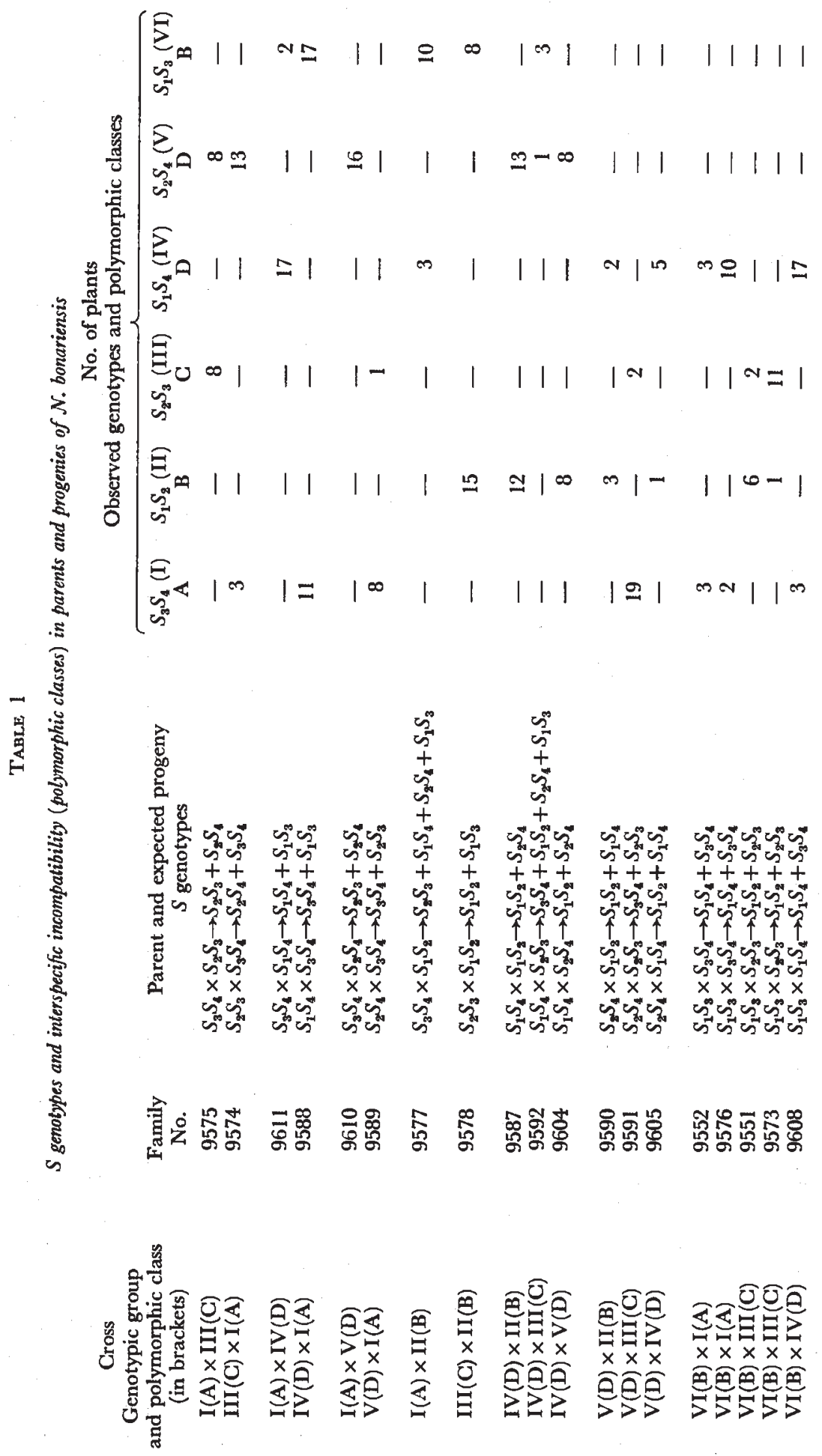




\section{(ii) Crosses involving abnormal plants}

In the family $9592\left(S_{1} S_{4} \times S_{2} S_{3}\right.$, cf. table 1) which, owing to poor seed set in the cross and poor germination, comprised only four plants there was one unthrifty plant (9592-4) that was female-sterile but pollen-fertile. This plant, as judged from pollen-tube studies, was partly S.C. and had the constitution $S_{2} S_{4}(\mathrm{~V})$, and, as expected, belonged to the polymorphic class D. A number of normal and male-sterile plants were crossed as females with plant 9592-4 and the behaviour of their progeny was studied. The results are given in table 2. Of the six families grown, four $(8405,8415,9655,8412)$, in general, produced the expected $S$ genotypic groups; in the remaining two families, however, the groups produced matched the expectation based on one of the alleles of the male parent being $S_{1}$ instead of $S_{2}$.

The appearance of the $S_{1}$ allele in the progeny where $S_{2}$ was expected can, of course, be due to contaimination of the pollen in the parental cross, and this cannot be ruled out. However, as already stated, the pollen parent 9592-4 was an exceptional plant in a number of ways. Unfortunately, this plant died before it could be rechecked for its $S$ constitution during the next season. It is possible that this plant was trisomic for the $S$-bearing chromosome and was triallelic $\left(S_{1} S_{2} S_{4}\right)$. In some branches the $S_{1}$-bearing chromosome was lost so that only the $S_{2}$ or $S_{4}$ alleles were present in the pollen, in others the $S_{2}$-bearing chromosome was lost so that only the $S_{1}$ or $S_{4}$ alleles were present in the pollen. This hypothesis is supported by the fact, shown from the pollen-tube studies, that the plant was self-compatible presumably due to competitive interaction in the pollen (Lewis, 1947; Pandey, 1956a, 1965; Brewbaker and Natarajan, 1960). Apparently, the pollen tubes with two $S$ alleles were inviable, for no triallelic plants were observed in the progeny.

As regards interspecific polymorphism, however, all plants again behaved exactly as expected on the basis of their $S$ genotypic constitution. It did not matter whether the plants were normal or abnormal in other respects, as long as the $S$ genotypic constitution could be determined the interspecific incompatibility relationship with the $S$ alleles was confirmed unequivocally.

\section{(iii) Bud-selfed progeny}

Bud-selfed progeny were grown from five out of six genotypes. In addition to poor germination of seeds most plants showed varying degrees of male and female sterility. Each plant was selfed and reciprocally crossed with its parental genotype. Plants which as females showed compatibility with the parental genotype were crossed among themselves, and also as male parents with the other five $S$ heterozygous genotypes. The results of these test crosses (table 3 ) revealed the $S$ genotypic constitution of each plant, including whether it was homozygous or heterozygous for $S$ alleles. In addition to the five parental heterozygous genotypes, four new homozygous genotypes $S_{1} S_{1}, S_{2} S_{2}, S_{3} S_{3}$ and $S_{4} S_{4}$ were recovered in the progeny.

All heterozygous plants behaved exactly like their respective parents in crosses with interspecific testers, N.l. and GM8. The homozygous genotypes, however, varied in this respect. Except for the progeny of the genotypic group III, $S_{2} S_{3}$, in which both the homozygous genotypes $S_{2} S_{2}$ and $S_{3} S_{3}$ belonged to the same polymorphic class as their parent $(\mathrm{C})$, the progeny of 


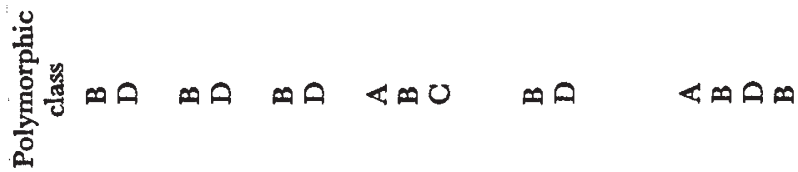

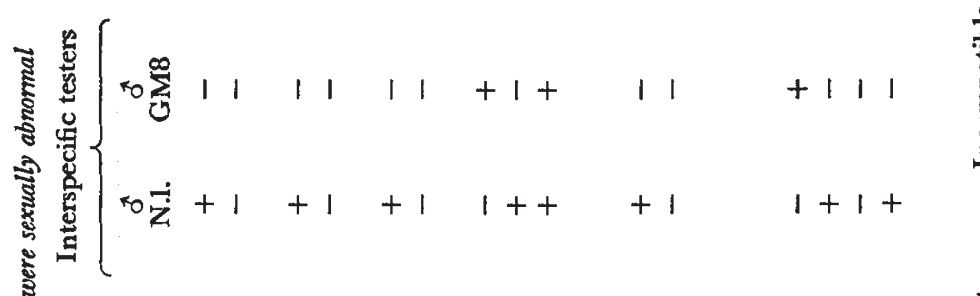

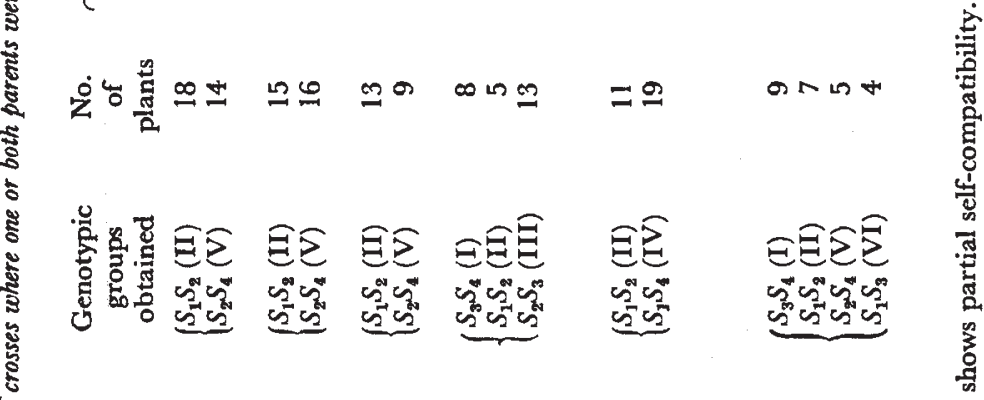

気

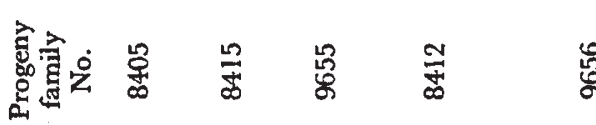

跑

है

总

㤩

\&̊․ㅇ

宓

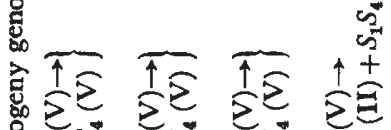

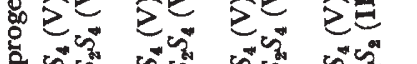

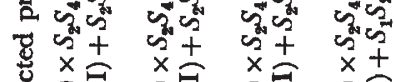

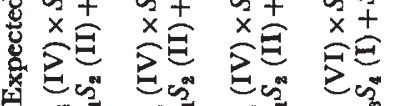

के के के के के के

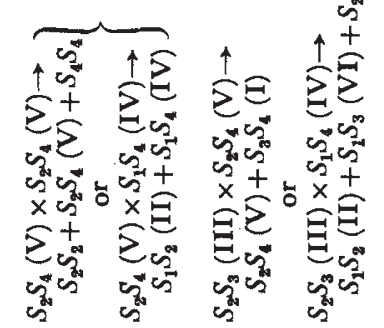

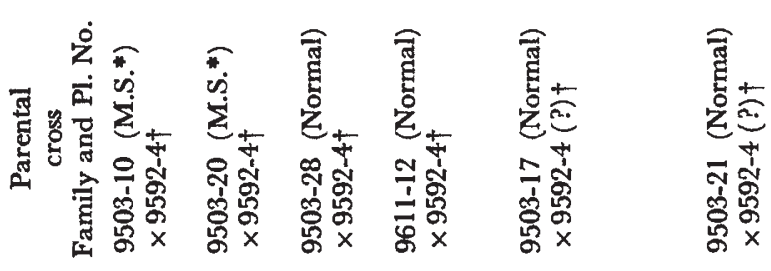


all other genotypic groups produced two homozygous genotypes which belonged to two different polymorphic classes, one being the same as that of its parent. Each homozygous genotype had its own characteristic polymorphic class irrespective of the parental genotypic group from which individual plants were derived.

\section{TABle 3}

$S$ genotypes and interspecific incompatibility (polymorphic classes) in bud-selfed progeny

Bud-selfed parent

$\begin{array}{cc}\text { Genotype } & \text { Group } \\ S_{3} S_{4} & \text { I } \\ S_{1} S_{2} & \text { II } \\ S_{2} S_{3} & \text { III } \\ S_{2} S_{4} & \text { V } \\ S_{1} S_{3} & \text { VI }\end{array}$

Progeny-No. of plants in each genotype

Total

No. of plants (polymorphic class)

\begin{tabular}{cll} 
Heterozygous & \multicolumn{1}{c}{ Homozygous } \\
$7-S_{3} S_{4}(\mathrm{~A})$ & $1-S_{3} S_{3}(\mathrm{C})$ & \\
$6-S_{1} S_{2}(\mathrm{~B})$ & $3-S_{1} S_{1}(\mathrm{~B}) ;$ & $1-S_{2} S_{2}(\mathrm{C})$ \\
$5-S_{2} S_{3}(\mathrm{C})$ & $1-S_{2} S_{2}(\mathrm{C}) ;$ & $1-S_{3} S_{3}(\mathrm{C})$ \\
$16-S_{2} S_{4}(\mathrm{D})$ & $3-S_{2} S_{2}(\mathrm{C}) ; 8-S_{4} S_{4}(\mathrm{D})$ \\
$3-S_{1} S_{3}(\mathrm{~B})$ & $4-S_{1} S_{1}(\mathrm{~B}) ; 2-S_{3} S_{3}(\mathrm{C})$
\end{tabular}

\section{(a) Dominance interaction in the style}

The comparative behaviour of the four homozygous and six heterozygous $S$ genotypes in respect to their interspecific incompatibility with two testers, N.1. and GM8, are highlighted in table 4. It can be seen from the table that styles with genotypes $S_{1} S_{2}$ and $S_{1} S_{3}$ reject GM8 pollen by virtue of the presence of the allele $S_{1}$, for homozygous styles having $S_{2}$ or $S_{3}$ allele alone accept GM8 pollen. Styles having the genotype $S_{2} S_{3}$, as expected, accept both N.l.

TABLE 4

Comparative interspecific incompatibility (polymorphic classes) in the 10 S-homozygous and -heterozygous genotypes possible from four different $S$ alleles

\begin{tabular}{|c|c|c|c|}
\hline \multirow[b]{2}{*}{$\begin{array}{l}\mathcal{N} . \text { bonariensis } \\
S \text { genotypes }\end{array}$} & \multicolumn{2}{|c|}{ Interspecific testers } & \multirow[b]{2}{*}{$\begin{array}{l}\text { Polymorphic } \\
\text { class }\end{array}$} \\
\hline & $\begin{array}{c}\text { o } \\
\text { N.1. }\end{array}$ & $\begin{array}{c}\sigma^{*} \\
\text { GM8 }\end{array}$ & \\
\hline \multicolumn{4}{|l|}{ Homozygous } \\
\hline $\begin{array}{l}S_{1} S_{1} \\
S_{2} S_{2} \\
S_{3} S_{3} \\
S_{4} S_{4}\end{array}$ & $\begin{array}{l}+ \\
+ \\
+ \\
-\end{array}$ & $\begin{array}{l}- \\
+ \\
+\end{array}$ & $\begin{array}{l}\text { B } \\
\text { C } \\
\text { C } \\
\text { D }\end{array}$ \\
\hline \multicolumn{4}{|l|}{ Heterozygous } \\
\hline $\begin{array}{l}S_{1} S_{2} \text { (II) } \\
S_{1} S_{3} \text { (VI) } \\
S_{2} S_{8} \text { (III) } \\
S_{1} S_{4} \text { (IV) } \\
S_{2} S_{4} \text { (V) } \\
S_{3} S_{4} \text { (I) }\end{array}$ & $\begin{array}{l}+ \\
+ \\
+ \\
- \\
-\end{array}$ & $\begin{array}{l}- \\
\overline{+} \\
\overline{-} \\
\overline{+}\end{array}$ & $\begin{array}{l}\text { B } \\
\text { B } \\
\text { C } \\
\text { D } \\
\text { D } \\
\text { A }\end{array}$ \\
\hline
\end{tabular}

and GM8 pollen. Styles with genotypes $S_{1} S_{4}$ and $S_{2} S_{4}$ reject the pollen of both testers by virtue of the presence of the allele $S_{4}$, for homozygous styles having the allele $S_{4}$ reject both types of pollen. These reactions of $S$ alleles in the diploid style have been termed independent, and are characteristic of 
stylar $S$ gene action in the gametophytic system of incompatibility (Lewis, 1947, 1954b; Pandey, 1956a).

When the genotype $S_{3} S_{4}$ is considered, however, a different picture emerges. Styles of this constitution accept GM8 pollen although they contain the allele $S_{4}$ which normally causes rejection of both N.l. and GM8 pollen. It is apparent that in this case the sister allele $S_{3}$, which causes acceptance of GM8 pollen, is dominant over the rejecting allele $S_{4}$. Another interesting feature highlighted by this interaction is the independence of the two faculties of the $S_{3}$ allele, one in relation to the N.l. pollen and the other to the GM8 pollen. The $S_{3}$ allele when present alone causes acceptance of both types of pollen while $S_{4}$ pollen when present alone causes rejection of both types of pollen. When in association, as in $S_{3} S_{4}$ styles, $S_{3}$ is dominant over $S_{4}$ only in relation to GM8 pollen but not in relation to N.l. pollen. In the latter case $S_{4}$ allele is able to assert its independent action (or dominance over $S_{3}$ ).

\section{(iv) Other pollen testers}

(a) N. noctiflora, N. forgetiana, N. alata and N. longiflora

Having obtained, in $\mathcal{N}$. bonariensis, plants homozygous for $S$ alleles, and thus having available all the 10 possible $S$ genotypes arising from four

TABLE 5

Interspecific incompatibility in the $10 \mathrm{~S}$-homozygous and -heterozvgous genotypes in $\mathcal{N}$. bonariensis, possible from four different $S$. alleles, when tested with the pollen of four other Nicotiana species

\begin{tabular}{|c|c|c|c|c|c|c|c|c|}
\hline \multirow{3}{*}{\multicolumn{2}{|c|}{$\begin{array}{c}\mathcal{N} \text { N. bonariensis } \\
\text { \& Parent }\end{array}$}} & \multicolumn{7}{|c|}{ o Testers } \\
\hline & & \multirow{3}{*}{$\begin{array}{l}\mathcal{N} . \text { noctiflora } \\
\text { (S.I.) }\end{array}$} & \multirow{2}{*}{\multicolumn{2}{|c|}{$\mathcal{N}$. forgetiana $\dagger$}} & \multirow{2}{*}{\multicolumn{2}{|c|}{$\mathcal{N}$. alata }} & \multicolumn{2}{|c|}{$\mathcal{N}$. longiflora (S.C.) } \\
\hline & & & & & & & & \\
\hline Genotype & Plant No. & & S.I. & S.C. & S.I. & S.C. & grandiflora & breviflora \\
\hline \multicolumn{9}{|l|}{ Homozygous } \\
\hline$S_{1} S_{1}$ & $8488-10 / 1$ & - & + & + & + & + & - & - \\
\hline$S_{2} S_{2}$ & $9548-1$ & - & + & + & + & + & - & - \\
\hline$S_{3} S_{3}$ & $8488-5 / 1$ & + & + & + & + & + & - & - \\
\hline$S_{4} S_{4}$ & $9681-5$ & + & + & + & + & + & - & - \\
\hline \multicolumn{9}{|c|}{ Heterozygous } \\
\hline$S_{1} S_{2}$ & 9587-19 & - & + & + & + & + & - & \\
\hline$S_{3} S_{4}$ & $9588-20$ & + & + & + & + & + & - & \\
\hline$S_{1} S_{3}$ & $9611-15$ & - & + & + & + & + & - & \\
\hline$S_{2} S_{4}$ & $9503-15$ & + & + & + & + & + & - & \\
\hline$S_{2} S_{3}$ & $9589-8$ & $+*$ & + & + & + & + & - & \\
\hline$S_{1} S_{4}$ & $9608-15$ & $+*$ & + & + & + & + & - & \\
\hline
\end{tabular}

S.C. $=$ Self-compatible.

$\dagger$ Tests with the pollen of this species give inconclusive results, producing seed-set in most crosses.

$S$ alleles (six heterozygous and four homozygous), it was thought desirable to extend the testing of these plants to include pollen of certain other species and strains of Nicotiana. They were crossed as females with normally S.I. species $\mathcal{N}$. noctiflora, $\mathcal{N}$. forgetiana and $\mathcal{N}$. alata, and two strains, var. grandiflora and var. breviflora, of the S.C. species $\mathcal{N}$. longiflora. Two plants, one S.I. and the other S.C., were used in each of the species $\mathcal{N}$. forgetiana and $\mathcal{N}$. alata. The results are given in table 5 . The pollen of $\mathcal{N}$. forgetiana and 
$\mathcal{N}$. alata, whether from S.I. or S.C. plant, was accepted by all $\mathcal{N}$. bonariensis styles although with $\mathcal{N}$. forgetiana an occasional inconsistent incompatibility was observed. (The cause for this is unknown and may be related to the extreme disparity between the lengths of the styles of the two species involved. A similar situation has been noted before between $\mathcal{N}$. bonariensis and $\mathcal{N}$. alata (Pandey, 1969a). It may be recalled that in an earlier test where $\mathcal{N}$. forgetiana plants of hybrid origin were used as testers $\mathcal{N}$. bonariensis styles showed polymorphism (Pandey, 1969b).) Pollen of the two varieties of S.C. $\mathcal{N}$. longiflora was, on the other hand, rejected by all $\mathcal{N}$. bonariensis styles. $\mathcal{N}$. bonariensis did not show polymorphism with regard to the different forms of any of the three species, $\mathcal{N}$. forgetiana, $\mathcal{N}$. alata and $\mathcal{N}$. longiflora.

\section{Dominance interaction in the style}

$\mathcal{N}$. bonariensis styles show polymorphism with regard to the pollen of S.I. $\mathcal{N}$. noctiflora, as already shown previously (Pandey, 1969b). In the present experiments, styles homozygous for the $S_{1}$ or $S_{2}$ allele reject pollen of $\mathcal{N}$. noctiflora, whereas those homozygous for the $S_{3}$ or $S_{4}$ allele accept them. As expected, the heterozygous $S_{1} S_{2}$ styles reject the pollen of $\mathcal{N}$. noctiflora while the heterozygous $S_{3} S_{4}$ styles accept them. Again, as expected on the basis of the gametophytic system of incompatibility, the heterozygous $S_{1} S_{3}$ styles, owing to the presence of the allele $S_{1}$, reject the pollen of $\mathcal{N}$. noctiflora. The situation in the heterozygous $S_{2} S_{4}$ styles, however, is contrary to expectation. These styles, despite the presence of the rejecting allele $S_{2}$, accept the pollen of $\mathcal{N}$. noctiflora. This would suggest that the accepting allele $S_{4}$ is dominant over the rejecting allele $S_{2}$. A similar interaction also occurs in heterozygous styles of the genotypes $S_{2} S_{3}$ and $S_{1} S_{4}$, although in these the dominance of $S_{3}$ over $S_{2}$ and of $S_{4}$ over $S_{1}$ is incomplete.

\section{(b) N. glauca}

The results of crosses of $\mathcal{N}$. bonariensis with seven testers from $\mathcal{N}$. glauca are given in table 6 . The testers include, in addition to the previously used S.I. plant GM8, two S.C. and four S.I. plants derived from the new family 8468. $\mathcal{N}$. bonariensis shows polymorphism with regard to the pollen of $\mathcal{N}$. glauca. As in previous studies (Pandey, 1968, 1969a, b), pollen of the two S.C. plants is generally rejected by S.I. plants of $\mathcal{N}$. bonariensis. In the present study, however, there is an incomplete rejection of this pollen by one genotype, the homozygous $S_{3} S_{3}$. All other homozygous and heterozygous genotypes show complete rejection in the stigma. Thus, in the same species $\mathcal{N}$. glauca, the S.C. plants 8468-4 and 8468-9 have the $S_{C}$ type of allele whereas the S.I. plants generally have the usual $S_{I}$ type of alleles.

\section{Unique reaction of the GM8 pollen}

As regards pollen of S.I. plants the results show a difference between the pollens of S.I. testers, a case not recorded previously. The homozygous $S_{4} S_{4}$ styles reject GM8 pollen but accept pollen of the four other S.I. testers. The remaining three homozygous styles, $S_{1} S_{1}, S_{2} S_{2}$ and $S_{3} S_{3}$, individually, behave alike with all five S.I. testers-the $S_{1} S_{1}$ styles reject all pollen and the $S_{2} S_{2}$ and $S_{3} S_{3}$ styles accept all pollen.

A similar difference in the pollen reaction among the S.I. testers is evident in tests with heterozygous plants, the pollen of GM8 again being different from the pollen of other S.I. testers. Considering the four new 
testers first, the heterozygous genotypes $S_{3} S_{4}, S_{2} S_{3}$ and $S_{2} S_{4}$ accept their pollen since the homozygous genotypes, $S_{2} S_{2}, S_{3} S_{3}$ and $S_{4} S_{4}$, the three alleles concerned, also accept them. On the other hand, the heterozygous $S_{1} S_{2}$, $S_{1} S_{4}$ and $S_{1} S_{3}$ genotypes reject their pollen since they all contain the allele $S_{1}$

TABLE $6 *$

Interspecific incompatibility in the $10 \mathrm{~S}$-homozygous and -heterozygous genotypes in $\mathcal{N}$. bonariensis with the pollen of six self-incompatible $\left(G M 8-S_{I} S_{C}\right.$, five others $\left.S_{I} S_{I}\right)$ and two self-compatible $\left(S_{C} S_{C}\right)$ plants of $\mathcal{N}$. glauca

d Testers $\mathcal{N}$. glauca

\begin{tabular}{|c|c|c|c|c|c|c|c|c|}
\hline \multicolumn{2}{|c|}{$\begin{array}{c}\mathcal{N} \text {. bonariensis } \\
\text { \& Parent }\end{array}$} & \multicolumn{7}{|c|}{ Plant No. } \\
\hline$\overbrace{\text { Genotype }}$ & Plant No. & $\begin{array}{l}\text { S.I. } \\
\text { GM8 }\end{array}$ & $\begin{array}{c}\text { S.I. } \\
8468-8\end{array}$ & $\begin{array}{c}\text { S.I. } \\
8468-11\end{array}$ & $\begin{array}{c}\text { S.I. } \\
8468-14\end{array}$ & $\begin{array}{c}\text { S.I. } \\
8468-17\end{array}$ & $\begin{array}{c}\text { S.C. } \\
8468-4\end{array}$ & $\begin{array}{l}\text { S.C. } \\
8468-9\end{array}$ \\
\hline Homozygou & & & & & & & & \\
\hline $\begin{array}{l}S_{1} S_{1} \\
S_{2} S_{2} \\
S_{3} S_{3} \\
S_{4} S_{4}\end{array}$ & $\begin{array}{l}8488-10 / 3 \\
9548-1 \\
8488-5 / 1 \\
9681-5\end{array}$ & $\begin{array}{l}- \\
+ \\
+\end{array}$ & $\begin{array}{l}- \\
+ \\
+ \\
+\end{array}$ & $\begin{array}{l}- \\
+ \\
+ \\
+\end{array}$ & $\begin{array}{l}- \\
+ \\
+ \\
+\end{array}$ & $\begin{array}{l}- \\
+ \\
+ \\
+\end{array}$ & $\begin{array}{l}- \\
\overline{+} \\
-\end{array}$ & $\begin{array}{l}- \\
+ \\
-\end{array}$ \\
\hline
\end{tabular}

\section{Heterozygous}

$\begin{array}{lllllllll}S_{3} S_{4} & 9588-20 & + & + & + & + & + & - & - \\ S_{1} S_{2} & 9587-19 & - & - & - & - & - & - & - \\ S_{2} S_{3} & 9589-8 & + & + & + & + & + & - & - \\ S_{1} S_{4} & 9608-15 & - & - & - & - & - & - & - \\ S_{2} S_{4} & 9503-15 & - & + & + & + & + & - & - \\ S_{1} S_{3} & 9611-15 & - & - & - & - & - & - & -\end{array}$

- Symbols same as in table 5. † Partial compatibility

which in the homozygous condition is known to cause rejection of this class of pollen.

Considering the GM8 pollen, five of the six heterozygous genotypes behaved with this pollen the same way as they did with the other testers. However, one, $S_{2} S_{4}$, behaved differently. The latter rejected the pollen of GM8 while it accepted the pollen of other testers. The difference in the two groups of testers, GM8 on the one hand and the four new testers on the other, lies in their reaction with the allele $S_{4}$. This allele accepts the pollen of the new testers but rejects that of GM8. The heterozygous genotype $S_{2} S_{4}$, therefore, rejects the pollen of GM8.

\section{Discussion}

\section{(i) $S$ alleles and interspecific incompatibility}

The association between $S$ alleles and interspecific crossability behaviour discovered in the previous study of four families of $\mathcal{N}$. bonariensis (Pandey, 1969 ) is fully substantiated by the present study of a large number of their progeny. Hybridisation between plants made no difference in the expression of this characteristic, the segregant progeny again showing the crossability behaviour peculiar to each $S$ genotypic constitution. In a total of approximately 600 plants studied (96-original families, 502-progenies) not a single plant was found which varied from the crossability behaviour characteristic of its $S$ genotype. A similar result has been reported from a previous 
study of approximately 600 plants in $\mathcal{N}$. alata (Pandey, 1964). The relationship, therefore, within the limits tested (1200 plants), is unbroken and complete.

The production and testing of $S$ homozygous plants further confirmed the central role of the $S$ alleles in the control of interspecific incompatibility. Each allele had its own characteristic behaviour in relation to pollen of one species, and this behaviour varied in relation to pollen of different species. In table 7 the four $S$ alleles of $\mathcal{N}$. bonariensis studied have been classified into two groups, "accepting" and "rejecting", in relation to the pollen of three species, $\mathcal{N}$. langsdorffi, $\mathcal{N}$. noctiflora and $\mathcal{N}$. glauca. It is obvious from the table that each allele is independent in its reaction to pollen of different species.

The incompatibility involved in these studies including others reported previously (Pandey, 1967, 1969a) is of the unilateral type, the reciprocals being compatible, and owes this reaction to the presence of specific $S$ alleles

TABLe 7

$S$-allele specificity in the styles of $\mathcal{N}$. bonariensis causing rejection or acceptance of pollen from different species

\begin{tabular}{|c|c|c|c|}
\hline $\begin{array}{c}\text { Classes } \\
\text { " Accepting " alleles }\end{array}$ & 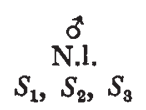 & $\begin{array}{c}\sigma \\
\mathcal{N} . \text { noctiflora } \\
S_{8}, S_{4}\end{array}$ & $\begin{array}{c}\stackrel{0}{ }^{*} \\
\mathcal{N} . \text { glauca* } \\
S_{2}, S_{3}, S_{4}\end{array}$ \\
\hline "Rejecting" alleles & $S_{4}$ & $S_{1}, S_{2}$ & $S_{1}$ \\
\hline
\end{tabular}

* The pollen of GM8, which is heterozygous $S_{I} S_{C}$, is excluded from this compilation, which is concerned only with usual $S_{I} S_{I}$ plants of $\mathcal{N}$. glauca.

in the style and pollen. It supports the earlier conclusion, that different forms of unilateral interspecific incompatibility observed among S.I. and S.C. species (i.e. S.I. $\times$ S.I., S.I. $\times$ S.C., S.C. $\times$ S.I. and S.C. $\times$ S.C.) are all primarily based on the specificity of $S$ alleles (Pandey, 1968).

(ii) Determination of interspecific incompatibility: gametophytic or sporophytic?

\section{(a) Allelic interactions in the style}

The comparative study of all the possible 10 genotypes, four homozygous and six heterozygous, from four different $S$ alleles, revealed certain interesting features of the $S$ gene in relation to interspecific incompatibility. One of the basic characteristics of the normal gametophytic system of intraspecific incompatibility is an independent action and full expression of both alleles in the diploid style. In a pollination a haploid pollen grain containing a $S_{I}$ allele which is also present in the style is invariably rejected irrespective of the presence of other kinds of stylar sister allele(s). The presence in the style of an associated compatible allele has no effect on the rejection caused by the incompatible allele. No interaction of $S$ alleles occurs.

In the present study, as indeed in similar other studies involving pollenstyle incompatibility, in an incompatible pollination of usual S.I. styles containing both a rejecting and an accepting allele it is impossible to distinguish between (1) independent action of the rejecting allele and (2) allelic interaction resulting in dominance of the rejecting allele over the accepting allele. Both alternatives would show identical responses-rejection of the pollen. The occurrence of only one allele out of four showing this kind of 
rejection makes three (50 per cent.) of the six possible $S$-heterozygous styles incompatible with one type of pollen. Such is the case with the allele $S_{4}$ in relation to the pollen of $\mathcal{N}$. langsdorffi $i$ and with the allele $S_{1}$ in relation to the pollen of the usual S.I. plants of $\mathcal{N}$. glauca (cf. tables 4,6 and 7). Thus, the function of the rejecting allele is exaggerated in expression in plant populations.

In investigations of interspecific incompatibility where usually all pollen of a species behaves alike and the determining variation occurs only in the stylar alleles, the action of the two categories of $S$ alleles, one accepting and the other rejecting the pollen, can be studied with a greater degree of discrimination than is possible in the study of intraspecific incompatibility. Here it is possible to test, unequivocally, the third possibility, (3) dominance
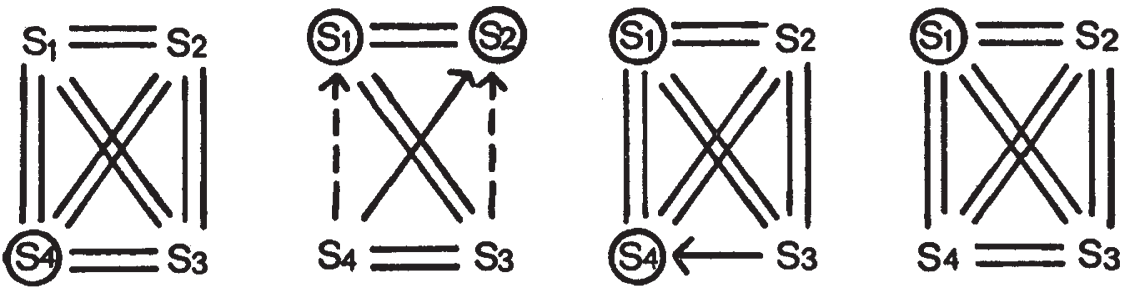

Figs. 1-4.-Diagrammatic presentation of $S$ allele interaction in the style of Nicotiana bonariensis. Of the three possible interactions, (i) dominance of the incompatible allele over the compatible allele, (ii) independent action of the incompatible allele, and (iii) dominance of the compatible allele over the incompatible allele, the first two cannot be distinguished and this has been shown by two parallel lines; the third has been shown by an arrow pointing from the dominant to the recessive allele. Arrow with broken lines shows incomplete dominance. The encircled alleles are " rejecting" alleles, the others are " accepting " alleles.

Fig. 1.-Pollen of $\mathcal{N}$. langsdorffi. Fig. 2.-Pollen of $\mathcal{N}$. noctiflora. Fig. 3.-Pollen of $\mathcal{N}$. glauca, strain GM8. Fig. 4.-Pollen of $\mathcal{N}$. glauca, usual S.I. plants.

of the accepting allele over the rejecting allele. If in a heterozygous style the accepting allele expresses itself despite the presence of an associated rejecting allele, the dominance of the former over the latter is indisputable. Such is the case with the heterozygous genotypes $S_{2} S_{4}$ and $S_{3} S_{4}$. Styles of the constitution $S_{2} S_{4}$ accept the pollen of $\mathcal{N}$. noctiflora, the accepting allele $S_{4}$ being dominant over the rejecting allele $S_{2}$. Similarly, styles of the constitution $S_{3} S_{4}$ accept the pollen of GM8, the accepting allele $S_{3}$ being dominant over the rejecting allele $S_{4}$ (cf. tables 5 and 6 ). A diagrammatical representation of $S$ allele interactions in relation to four different pollen testers has been given in figs. 1-4. These results undoubtedly show that the $S$ gene action in the style with regard to interspecific incompatibility is truly sporophytic. The allelic interactions are specific for the pollen of particular species and have no relationship with the behaviour of the individual alleles towards the pollen of other species (cf. table 7).

\section{(b) Inherent ability of genes for allelic interaction}

In the gametophytic system of intraspecific incompatibility, although the expression of incompatibility on the female side occurs in the diploid tissue of the sporophyte, the gametophytic type of reaction is assured by the independence of $S$-gene action. Thus, in the evolution of gametophytic 
system of incompatibility there has been a selection for independent action of $S$ alleles in the style. This selection apparently did not affect the interspecific incompatibility-controlling-elements of the $S$ complex, the alleles of which may show ability to interact. A similar ability to interact is displayed in the diploid pollen of autotetraploids, where again no selection has operated to exclude interaction.

Since the l-locus multiallelic gametophytic system is believed to be the primary form of self-incompatibility (Whitehouse, 1950; Lewis and Crowe, 1958; Pandey, 1960b), the expression of dominance or independent action of $S$ alleles whenever two alleles occur in the same cell which has not been subjected to selection favouring any particular kind of allelic interaction, shows that each allele, in a specific genetic environment, may have its own peculiar ability to interact with another allele. A particular allelic interaction may, however, be selected under certain circumstances either through modification of the genetic environment, or exclusion of alleles with unwanted interactions, or both (Pandey, 1957a, 1960a). Allelic interactions in the pollen and style, showing considerable variation between different pairs of alleles, is a common feature of the homomorphic sporophytic system of incompatibility, which is believed to be secondarily derived from the originally gametophytic system (Pandey, 1960b) and has no requirement for selection against allelic interactions.

\section{(c) Absence of competitive interaction in the style}

By necessity, competitive interaction which brings about a breakdown of self-incompatibility (Lewis, 1947; Pandey, 1956a) can not occur in the styles of fully functional gametophytic and sporophytic systems of intraspecific incompatibility. In the present study of $S$ gene interaction, in cases where two different incompatibility (rejecting) alleles occur together in the same style, there is an absence of competitive interaction, although no selection could have operated to eliminate it. The heterozygous styles $S_{1} S_{4}$, having both $S_{1}$ and $S_{4}$ alleles incompatible with GM8 pollen, reject this pollen. Similarly, heterozygous styles $S_{1} S_{2}$, having both $S_{1}$ and $S_{2}$ alleles incompatible with $\mathcal{N}$. noctiflora pollen, reject this pollen. In the earlier studies in $\mathcal{N}$. alata (Pandey, 1964), heterozygous styles $S_{\mathrm{F} 10} S_{\mathrm{F} 11}$, having both $S_{\mathrm{F} 10}$ and $S_{\mathrm{F} 11}$ alleles incompatible with $\mathcal{N}$. langsdorffi pollen, rejected this pollen.

All evidence suggests that competitive interaction is a peculiar property of the pollen and is limited to polyploid plants (or plants with pollen having more than one $S$ allele) of the gametophytic system of incompatibility. In all other situations only a dominant or independent type of interaction occurs. It has been proposed that competitive interaction is a secondary phenomenon of the $S$ gene action in the male gametophyte. It occurs late during germination, or even later in the pollen tube, when the specific incompatibility precursors are converted into specific incompatibility substances, and probably involves competition for the specific enzyme(s) presumably responsible for the conversion (Pandey, 1962c).

\section{(d) Allelic interactions in the pollen}

In the extensive study in Nicotiana illustrating the $S$-gene control of interspecific incompatibility, polymorphism has been discovered on the female side only. No polymorphism was found on the male side in a number of 
S.I. species studied, all pollen of S.I. plants of the same species behaving identically (Pandey, 1969a, b).

Why, then, should the pollen of S.I. GM8 be different from that of the other new S.I. plants of $\mathcal{N}$. glauca? The answer appears to lie in the fact, stated earlier in Materials and Methods, that GM8 is heterozygous, containing two different forms of $S$ alleles, a normal self-incompatibility allele $S_{I}$, and a mutant self-compatibility allele $S_{C}$ which, when present in pollen, causes that pollen to be rejected by a S.I. style. The reaction of pollen of this heterozygous plant $S_{I} S_{C}$ is apparently different from that of plants which have both alleles of the same form $\left(S_{I} S_{I}\right)$. It is an example of $S$ allele interaction in the pollen. And this leads to a second question.

The second question is: Why is it that only styles with the allele $S_{4}$ react differently with the pollen of GM8 while styles with the other alleles, $S_{1}, S_{2}$ and $S_{3}$, behave alike with both classes of S.I. testers, GM8 as well as the four new testers? The answer seemingly lies simply in differences in allelic characteristics. If the four new testers are assumed to belong to the common class of S.I. plants having two different alleles of the same $S_{I}$ form of the gene-which they have proved to be in tests so far (unpub.)-then the absence of a difference in the reactions of the alleles $S_{1}, S_{2}$ and $S_{3}$ as regards the two classes of pollen testers may mean that GM8 pollen is equivalent to that of the normal S.I. group of plants when reacting with styles having $S_{1}, S_{2}$ or $S_{3}$, but it is different when it reacts with styles having $S_{4}$. This would suggest that in the pollen of GM8 $\left(S_{I} S_{C}\right)$, in the case of the former reactions the $S_{I}$ allele is either dominant over the $S_{C}$ allele or has an independent action, while in the case of the latter reaction the $S_{C}$ allele is dominant over the $S_{I}$ allele. These results imply that there is a sporophytic reaction in the pollen of GM8.

\section{(e) Phases in the S-gene expression and the nature and evolution of dominance}

The present results in the pollen of $\mathcal{N}$. glauca plant GM8 $\left(S_{I} S_{C}\right)$, where two different forms of alleles occur in the same plant and show allelic interaction, strongly suggest that in this plant there is a precocious, sporophytic (premeiotic, or precytokinetic) action of the specificity producing elements either of the $S_{C}$ allele alone, or of both the $S_{C}$ and $S_{I}$ alleles. In the incompatibility reaction in the pollen of GM8 the dominance relationship-whether the $S_{I}$ is dominant over the $S_{C}$ or the $S_{C}$ is dominant over the $S_{I}$-is not fixed but can be either way, being determined late, after pollination, by the specific $S_{I}$ allele present in the style (cf. tables 4 and 6). This suggests that in GM8 pollen, in spite of eventual dominance interaction both alleles are initially expressed, producing their respective, specific, primary incompatibility precursors. One way this could be possible is if the $S_{C}$ action occurs sporophytically but the $S_{I}$ action is still gametophytic. Thus in 50 per cent. of the pollen, having the allele $S_{I}$, both alleles will be expressed independently without interaction during this pre-pollination phase. The other 50 per cent. of the pollen, having the expression of the $S_{C}$ allele alone, would normally be rejected by a style having a $S_{I}$ allele. In the pollen having the $S_{I}$ allele, the expression of dominance interaction occurs at the pollen germination and tube growth phase, after the pollen has come in contact with the stigma. As discussed above, this presumably relates to the process of conversion of the incompatibility precursors into incompatibility substances. The situation may be described as "partly sporophytic". 
Ordinarily, in interspecific incompatibility between S.I. species, where the different alleles of a pollen parent belong to the same usual $S_{I}$ form, e.g. $S_{1} S_{2}$, all pollen of the species behave alike irrespective of the possible differences in the allelic primary specificity. This indicates that there is no interaction and that the action of the primary specificity elements, under these conditions, may be gametophytic. (Normally, the interspecific specificity, however, does not interfere with the intraspecific specificity for as discussed above, the former is physiologically expressed only when the intraspecific, secondary specificity is unable to express itself owing to the disparity in the polygenic backgrounds of the pollen and the style. Thus the expression of the two specificities alternates between the two.) For, if the action of the primary specificity elements of the $S_{I}$ alleles is assumed to be sporophytic one might expect variation in the pollen reaction owing to interaction between the two allelic primary specificities, as suggested from the observations in the pollen of GM8.

The $S$-gene studies thus provide a special insight into the still incompletely understood problem of the nature and evolution of allelic dominance. In the present context they underline the significance of the phase difference between the "primary gene action" occurring before pollination and the " incompatibility reaction" occurring after pollination, and elucidate how interaction could occur at the incompatibility reaction rather than the primary gene action phase. Natural selection modifying genetic interactions may, possibly, occur at one or the other, or both, phases. Further light on this subject, with particular reference to the expression of the primary specificity, may be shed when detailed studies of the new S.I. $\mathcal{N}$. glauca plants are completed.

\section{(f) $S_{I}$ and $S_{C}$ alleles and the time of the $S$-gene action}

$\mathcal{N}$. glauca is the only species in the genus Nicotiana which has two distinct forms of pollen in the same species: (1) pollen of S.I. plants which are accepted by S.I. styles, and (2) pollen of S.C. plants which are rejected by S.I. styles. The species therefore offers a rare opportunity to study interaction between distinctive forms of alleles which normally occur in different species. Investigation of allelic interactions in the latter situation through studies of interspecific hybrids is generally complicated by pollen sterility and polygenic effects (Pandey, 1968).

The present study has shown that there is sporophytic action of $S$ alleles in the style for the determination of interspecific incompatibility. It has also shown that when two distinct forms of $S$ alleles, for example $S_{I}$ and $S_{C}$, occur in the same plant, the pollen reaction, at least in relation to the $S_{C}$ allele, may also be sporophytic. There are cases reported in the literature in which a precocious action of a particular unit, or of a major part, of the $S$ gene complex leading to varying degrees of sporophytic reaction is assumed to occur on account of the presence of a certain additional mutant allele, or an alien cytoplasm from a S.C. species. In a cross between S.I. Solanum sparsipilum (S. aracc-papa) and S.I. S. chacoense (S. subtilius) (Pushkarnath, 1953) the determination of the incompatibility alleles in the $F_{1}$ hybrids is sporophytic, presumably due to the presence of the mutant allele " $\mathrm{R}$ " at another locus (Pandey, 1957b). In Oenothera, interspecific hybrids between S.I. O. pallida $\left(\sigma^{*}\right)$ and S.C. $O$. trichocalyx (o), having $S_{I}$ and $S_{f}$ forms of alleles respectively, showed partially sporophytic control of incompatibility (Crowe, 1955; Pandey, 1968). It 
was suggested that in Oenothera hybrids having the cytoplasm of the S.C. species, the $S$-gene elements controlling the production of the presumed specific pollen growth substance acted precociously before cytokinesis (sporophytic) while the elements controlling the presumed specific incompatibility precursors acted, as is normal for gametophytic action, after cytokinesis. Similarly, a partly sporophytic action of $S$ alleles, owing to the presence of a duplicate $S$ locus with two forms of mutant alleles, has been proposed to explain intraspecific incompatibility in Solanum pinnatisectum (Pandey, 1962d). Sporophytic control of incompatibility has been suggested to occur in interspecific Lycopersicon hybrids between S.I. and S.C. species having $S_{I}$ and $S_{C}$ forms of alleles respectively (McGuire and Rick, 1954).

In hybrids between S.I. Nicotiana alata ( ${ }^{*}$ ) and S.C. $\mathcal{N}$. langsdorffi (o), which have been tested on a very limited scale (Anderson and de Winton, 1931 ; Pandey, 1964), the situation is ambiguous. As stated earlier, $\mathcal{N}$. alata has two kinds of self-incompatibility alleles, the more numerous $S_{I}$ alleles $\left(S_{1}, S_{2}, S_{3}, \ldots\right.$, etc.) which when present in the style allow that style to accept the $S_{f}$ pollen of $\mathcal{N}$. langsdorffi and the $S_{F I}$ alleles, of which only two $S_{\text {F10 }}$ and $S_{\text {F11 }}$ have been found, which when present in the style allow that style to reject the $S_{f}$ pollen. The interspecific hybrids having the constitution $S_{I} S_{f}$ $\left(S_{1} S_{f}, S_{2} S_{f}\right.$, etc.) are usually self-compatible. This may suggest that the $S$ gene action is gametophytic, but the alternative that the $S$ gene action in the pollen is sporophytic with the $S_{f}$ allele being dominant over the $S_{I}$ alleles tested, cannot be ruled out. Similarly in the $S_{\mathrm{F} 10} S_{f}$ and $S_{\mathrm{F} 11} S_{f}$ hybrids which are both self-incompatible the reaction can be interpreted on the basis of either the gametophytic or the sporophytic action. There is a possibility that further work on hybrids might reveal cases of dominance of a $S_{I}$ allele over the $S_{f}$ or of the $S_{f}$ over a $S_{F I}$ allele, thus providing a clear evidence for sporophytic action.

It has been proposed earlier (Pandey, 1968, 1969b) that, intraspecifically, in the pollen the secondary specificity which governs the intraspecific incompatibility is dominant (epistatic?) over the primary specificity which governs the interspecific incompatibility. Interspecifically, however, when the polygenic backgrounds of the two species are sufficiently distinct, the dominance of the secondary specificity over the primary specificity is lost and the primary specificity is expressed. With this hypothesis, in interspecific pollinations between two S.I. species where both have usual $S_{I}$ alleles, the action of the primary as well as the secondary specificity elements could be gametophytic, but whether or not the actual expression of the interspecific incompatibility occurs-conversion of specific precursors into specific incompatibility substances-is governed by the relative polygenic backgrounds of the pollen and style.

\section{(iii) Different forms of self-compatibility alleles and the time of their action in the pollen}

In $\mathcal{N}$. bonariensis, homozygous S.I. styles $S_{1} S_{1}, S_{2} S_{2}$ and $S_{4} S_{4}$, as expected, reject the pollen of S.C. plants of $\mathcal{N}$. glauca $\left(S_{C} S_{C}\right)$. However, homozygous styles of the constitution $S_{3} S_{3}$ partially accept them. Unpublished results in $\mathcal{N}$. glauca show that there are within this species rare $S_{I}$ alleles which when present in the homozygous condition in the style allow that style to accept $S_{C}$ pollen, and the resultant hybrid plants from such pollinations 
$\left(S_{I} S_{C}\right)$ are self-compatible. There are other similar examples of rare clones in S.I. Solanum species (11 clones in $S$. chacoense and 1 clone each in $S$. soukupii and $S$. vernei), styles of which accept the pollen of S.C. Solanum verrucosum $\left(S_{C} S_{C}\right)$, while the majority of other clones of these species reject this pollen (Grun and Radlow, 1961 ; Pandey, 1962b). As in $\mathcal{N}$. glauca, S.I. plants are also found infrequently in S.C. S. verrucosum (Magoon et al., 1958; Cipar et al., 1964).

The S.C. plants in $\mathcal{N}$. alata and $\mathcal{N}$. forgetiana used as pollen testers in the present crosses behaved identically with the S.I. plants. Their pollen was acceptable on all S.I. styles (cf. table 5). Similar behaviour of pollen (having the allele named here " $\mathrm{S}_{0}$ ") occurs in S.C. plants obtained through spontaneous and induced mutations in the regulatory (not specificity) elements of the $S$ gene (Lewis, 1951; Pandey, 1956b).

$S$ pollen of $\mathcal{N}$. langsdorffi is accepted by most S.I. styles and rejected by some (Anderson and de Winton, 1931; Pandey, 1964, 1967, 1969a). In contrast, $S_{C}$ pollen of $\mathcal{N}$. glauca (and $S$. verrucosum) is rejected by most S.I. styles and accepted by some. As opposed to both $S_{f}$ and $S_{C}$ pollen, which are accepted by at least some S.I. styles, there is a third class of pollen, having the allele called here " $S_{C n}$ ", which are invariably rejected by all S.I. styles. The last class of pollen occurs in a large number of wholly S.C. species, which are further divisible into groups having distinct forms of self-compatibility alleles, designated here as $S_{C_{1}}, S_{C_{2}}, S_{C_{3}}$, etc. This class is discernible on the basis of unilateral cross-incompatibility behaviour among these S.C. species (Pandey, 1968, 1969b).

Thus, there is a stepwise gradation in the cross-incompatibility behaviour of the pollen of S.C. plants, which is revealed by the increasing degree of rejection of these pollens by S.I. styles. The increase in rejection of the pollen is associated, in a general way, with the relative age of self-compatibility in the parent species, the older the self-compatibility the greater the rejection, the rejection becoming finally complete in species which are wholly S.C. and in which the self-compatibility is relatively ancient. The suggested allelic progression in the pollen rejection by S.I. species is as follows:

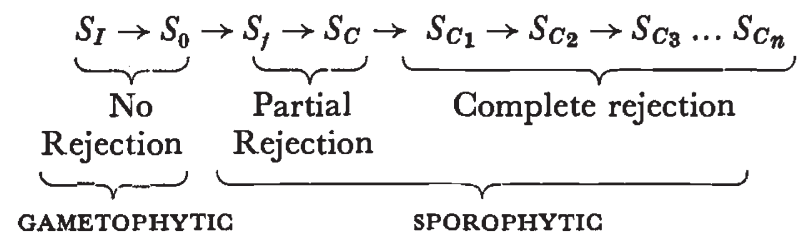

There appears to be a progressive relationship between the two phenomena, the extent of incompatibility of the pollen, and the time of the $S$ gene action. The normal $S_{I}$ and, usually, the recently mutated $S_{0}$ alleles, give the least cross-incompatible pollen and show fully gametophytic action; $S_{f}$ and $S_{C}$ alleles give progressively more cross-incompatible pollen and show relatively precocious, and hence partially sporophytic, $S$-gene action (as discussed earlier in (ii) (f)); and finally, $S_{C_{n}}$ alleles $\left(S_{C_{1}}, S_{C_{2}}, S_{C_{3}}, \ldots\right)$ give entirely cross-incompatible pollen and show fully sporophytic action.

The stepwise gradation in the extent of rejection of the pollen, having different forms of self-incompatibility and self-compatibility alleles, strongly supports the erosion hypothesis of the evolution of $S$-gene polymorphism (Pandey, 1968, 1969b). The massive evidence obtained from the study of 
incompatibility in the genus Nicotiana is in full agreement with the previously proposed theory of the evolution of the $S$-gene complex.

Acknowledgment.- $\mathrm{I}$ am indebted to Mr G. B. Petterson for expert technical assistance.

\section{REFERENGES}

ANDERSON, E., AND DE wiNTON, D. 1931. The genetic analysis of an unusual relationship between self-sterility and self-fertility in Nicotiana. Ann. Mo. bot. Gdn., 18, 97-116.

BREWBAKER, J. L., AND NATARAJAN, A. T. 1960 . Centric fragments and pollen-part mutation of incompatibility alleles in Petunia. Geretics, 45, 699-704.

GIPAR, M. S., PELOQUIN, S. J., AND HOUGAS, R. W. 1964. Variability in the expression of selfincompatibility in tuber-bearing diploid Solanum species. Amer. Pot. Four., 41, 155-162.

CROWE, L. K. 1955. The evolution of incompatibility in species of Oenothera. Heredity, 9, 293-322.

DARLington, C. D., AND MATHER, K. 1949. The Elements of Genetics. George Allen \& Unwin, London.

DARLINGTON, C. D. 1958. The evolution of Genetic Systems, 2nd ed. Oliver and Boyd, London and Edinburgh.

DARLINGTON, C. D. 1971. The Evolution of polymorphic systems. In Ecological Genetics and Evolution (ed. R. Creed). Blackwell, Oxford and Edinburgh.

EAST, E. M., AND MANGEISDORF, A. J. 1925. A new interpretation of the heredity behaviour of self-sterile plants. Proc. Natl. Acad. Sci. U.S., 11, 166-183.

FORD, E. B. 1964. Ecological Genetics. Methuen, London; Wiley, New York.

GRUN, P., AND RADLOW, A. 1961. Evolution of barriers to crossing of self-incompatible with self-compatible species of Solanum. Heredity, 16, 137-143.

LEWIS, D. 1947. Competition and dominance of incompatibility alleles in diploid pollen. Heredity, 1, 85-108.

LEWIs, D. 1949. Incompatibility in flowering plants. Biol. Revs., 24, 472-496.

LEWIS, D. 1951. Structure of the incompatibility gene. III. Types of spontaneous and induced mutation. Heredity, 5, 399-414.

LEWIS, D. 1954a. Incompatibility in relation to physiology and genetics. 8th Int. Congr. Bot., 9, 124-132.

LEWIs, D. 1954b. Comparative incompatibility in angiosperms and fungi. Adv. Genet., 6, 235-285.

LEWIS, D., AND CROWE, L. K. 1954. Structure of the incompatibility gene. IV. Types of mutation in Prunus avium L. Heredity, 8, 357-363.

LEWIS, D., AND CROWE, L. K. 1958. Unilateral interspecific incompatibility in flowering plants. Heredity, 12, 233-256.

MAGOON, M. L., COOPER, D. C., AND HOUGAS, R. W. 1958. Induced polyploids of solanums and their crossability with $S$. tuberosum. Bot. Gaz., 119, 224-231.

mather, x. 1943. Specific differences in Petunia. I. Incompatibility. F. Genet., 45, 215-235.

MATHER, x. 1955. Polymorphism as an outcome of disruptive selection. Evolution, 9, 52-61.

MATHER, K., AND DE WINTON, D. 1941. Adaptation and counter-adaptation of the breeding system in Primula. Ann. Bot., N.S., 5, 297-311.

MCGUIRE, D. C., AND RICK, C. M. 1954. Self-incompatibility in species of Lycopersican sect. Eriopersicon and hybrids with L. esculentum. Hilgardia, 23, 101-124.

PANDEY, K. K. 1956a. Incompatibility in autotetraploid Trifolium pratense. Genetics, 41, 353-366.

PANDEY, K. K. 1956b. Mutations of self-incompatibility alleles in Trifolium pratense and T. repens. Genetics, 41, 327-343.

PANDEY, K. K. 1957a. Genetics of self-incompatibility in Physalis ixocarpa Brot. A new system. Am. F. Bot., 44, 879-887.

PANDEY, K. K. 1957b. A self-compatible hybrid from a cross between two self-incompatible species in Trifolizm. F. Hered., 48, 278-281.

PANDEY, K. K. 1960a. Self-incompatibility system in two Mexican species of Solanum. Nature, 185, 483-484.

PANDEY, K. K. 1960b. Evolution of gametophytic and sporophytic systems of self-incompatibility in angiosperms. Evolution, 14, 98-115. 
PANDEY, K. K. 1961. $S$ allele mutations and components of the $S$ gene. Heredity, 16, 239. PANDEY, K. K. 1962a. A theory of $S$ gene structure. Nature, 196, 236-238.

PANDEY, K. K. 1962b. Interspecific incompatibility in Solanum species. Am. 7. Bot., 49, 874-882.

PANDEY, K. K. 1962c. Interactions of $S$ alleles in diploid pollen. Nature, 195, 205-206.

PANDEY, K. K. 1962d. Genetics of incompatibility behaviour in the Mexican Solanum species, S. pinnatisectum. Zeit.f. Verebung., 93, 378-388.

PANDEY, K. K. 1963. Stigmatic secretion and bud-pollinations in self- and cross-incompatible plants. Naturwissenschaften, 50, 408-409.

PANDEY, K. K. 1964. Elements of the $S$-gene complex. I. The $S_{F I}$ alleles in Nicotiana. Genet. Res., Camb., 5, 397-409.

PANDEY, K. K. 1965. Centric chromosome fragments and pollen-part mutation of the incompatibility gene in Nicotiana alata. Nature, 206, 792-795.

PANDEY, K. K. 1967. S-gene polymorphism in Nicotiana. Genet. Res., Camb., 10, 251-259.

PANDEY, K. K. 1968. Compatibility relationships in flowering plants: Role of the $S$-gene complex. Amer. Nat., 102, 475-489.

PANDEY, K. x. 1969a. Elements of the $S$-gene complex. IV. $S$-allele polymorphism in Nicotiana species. Heredity, 24, 601-619.

PANDEY, K. K. 1969b. Elements of the S-gene complex. V. Interspecific cross-compatibility relationships and theory of the evolution of the $S$ complex. Genetica, 40, 447-474.

PUSHKARNATH. 1953. Studies on sterility in potato. IV. Genetics of incompatibility in Solanum aracc-papa. Euphytica, 2, 49-58.

SHEPPARD, P. M. 1953. Polymorphism, linkage and the blood groups. Am. Nat., 87, 283294.

WHITEHOUSE, H. L. K. 1950. Multiple-allelomorph incompatibility of pollen and style in the evolution of the angiosperms. Ann. Bot., N.S., 14, 199-216. 